\title{
Why can't every year be a National Year of Reading? An evaluation of the NYR in Yorkshire.
}

Carolynn Rankin, Avril Brock and Jackie Matthews

\begin{abstract}
An evaluation of the National Year of Reading in Yorkshire was conducted by Leeds Metropolitan University in response to a brief from Museums, Libraries and Archives (MLA), Yorkshire. This paper outlines the development and planning of phase one of this small scale qualitative research project and the analysis of the initial results which looks at the impact of NYR on the organisations that delivered the campaign and their work with target groups. The Generic Social Outcomes and the National Indicators were used to develop a theoretical framework. Data were gathered via in depth interviews and focus groups with NYR steering group partners in Calderdale and North Lincolnshire, selected as the two case study authorities. The use of MAXQDA computerassisted qualitative data analysis software (CAQDAS) enabled data and coding structures to be stored and will facilitate comparison in this longitudinal study. This evaluation will provide material that local library authorities can use for advocacy with a range of audiences including local and central government.
\end{abstract}

\section{Introduction to the National Year of Reading evaluation project}

The National Year of Reading (NYR) campaign in 2008 was about celebrating and encouraging reading in all its forms. The NYR campaign ran from January to December with organisations and local authorities asked to pledge and plan their

\section{Authors}

Carolynn Rankin is a Chartered Librarian and senior lecturer in the School of Applied Global Ethics, Leeds Metropolitan University. Her research interests include the evaluation of library and information services and the provision of early years libraries.

Email: c.rankin@leedsmet.ac.uk

Dr Avril Brock is a principal lecturer in childhood and early years in the Carnegie Faculty, Leeds Metropolitan University, researching in professionalism, early language and play.

Jackie Matthews is a PhD candidate at the University of Wales, Bangor and worked part-time as a research assistant on the NYR research project. 
support between January and March. Delivery of the NYR was launched in April 2008 led by the National Literacy Trust on behalf of the Department for Children, Schools and Families, supporting ongoing work to achieve national literacy targets, engage parents and families in reading with their children and develop adult literacy. The key values for the year long social marketing campaign were diversity, creativity and partnership. In Yorkshire a partnership of MLA Yorkshire, Renaissance Yorkshire and Arts Council England, Yorkshire jointly commissioned a regional co-ordinator for NYR with the remit of co-ordination, strategic intervention, legacy development and corporate engagement. To contribute to work already underway on the evidence impact of the cultural sector, the NYR Yorkshire Steering Group also sponsored a longitudinal evaluation of the NYR in Yorkshire. Carolynn Rankin and Avril Brock of Leeds Metropolitan University were appointed by MLA Yorkshire in August 2008 to undertake the evaluation research for the clients. This paper outlines the development and planning of this small scale qualitative research project, and the analysis of the initial results for the phase one interim report which looks at the impact of NYR on the organisations that delivered the campaign and their work with target groups. It is interesting to consider the change of emphasis in looking at the social potential of library projects. In their book about evaluating the impact of libraries, Markless \& Streatfield (2006:44) discuss the first National Year of Reading which ran a decade ago in 1998-99. They note that there were numerous plans and energy, but most had no evaluation criteria attached - the evidence was almost all process performance indicators. Most local authorities had backed away from the more difficult questions about impact evaluation during the first National Year of Reading.

\section{Overview of the NYR in Yorkshire project}

The development of the brief and specification for the consultancy project was coordinated by MLA Yorkshire and required that the qualitative research should incorporate use of the MLA's Generic Social Outcomes. The aim of this longitudinal research was to investigate the efficacy of the National Year of Reading programme in Yorkshire as it relates to the place shaping and social inclusion targets of the NYR. The overall objectives were to investigate the impact of the NYR in sample local authorities in relation to

- Target beneficiaries

- Partnership and cross departmental working

The NYR campaign was delivered in 15 local authorities in Yorkshire and the Humber. In conjunction with the Leeds Metropolitan University research team the Yorkshire steering group decided to sample two contrasting authorities, one predominantly rural, and the other urban. Calderdale Libraries and North Lincolnshire Libraries were invited to participate, along with the departments and organisations involved in the NYR steering groups of those two authorities.

Contact with the key senior library personnel in Calderdale and North Lincolnshire was initiated by Erica Ramsay in her role as Regional Participation and Inclusion Advisor for MLA Yorkshire. Ethical principles permeate all aspects of research, particularly in relation to issues of potential harms to participants, 
informed consent, anonymity and confidentiality. At all stages in a research project it is important to scrutinise the methodology to ensure that processes proceed ethically without compromising the validity of the research (Cohen et al., 2003). The direct route to participants negotiated by the MLA facilitated timely access for the Leeds Metropolitan University research team and was of particular advantage due to the short timescale for phase one. An initial meeting between the client, representatives of the Calderdale and North Lincolnshire local authority library services and the research team took place in early September 2008. At this project initiation stage it was important to establish a rapport between the client, researchers and participants in order to communicate key messages about the project objectives, agree timescales and facilitate a partnership approach. It was proposed that the case study approach would enable a detailed and intensive analysis of NYR activities; there was no intention to undertake a comparison of the two case study authorities.

\section{Project planning and timescale}

The first phase of the evaluation project in Yorkshire ran between September and December 2008. The project plan for phase one is shown in the Gantt chart in Figure 1 below.

\begin{tabular}{|l|l|l|l|l|}
\hline Project tasks & Sep & Oct & Nov & Dec \\
\hline $\begin{array}{l}\text { Initiate project - meet regional NYR steering group } \\
\text { to agree sample authorities } \\
\text { Meet representatives from sample authorities }\end{array}$ & & & & \\
\hline $\begin{array}{l}\text { Seek researcher ethical approval from Leeds } \\
\text { Metropolitan University International Faculty }\end{array}$ & & & & \\
\hline Prepare project plan & & & \\
\hline Develop questionnaires and interview schedules & & & & \\
\hline $\begin{array}{l}\text { Undertake initial fieldwork with two selected local } \\
\text { authorities - gather social impact data }\end{array}$ & & & & \\
\hline Meeting with NYR regional project steering group & & & & \\
\hline Appoint research assistant to help transcribe data & & & & \\
\hline Transcribe, collate and analyse results & & & & \\
\hline $\begin{array}{l}\text { Interim Report on phase one of evaluation to MLA } \\
\text { Yorkshire \& NYR regional steering group }\end{array}$ & & & & \\
\hline
\end{tabular}

\section{Figure 1: Gantt chart showing project plan for phase one of NYR in Yorkshire}

A Gantt chart is a useful, and simple, way of representing the various stages of a research project by showing the key tasks against the timescales for their completion. It can be a useful tool for research project staff in helping to manage time and also for communicating with client and other stakeholders. 
The Gantt project chart also provided a starting point for discussing practical planning issues in arranging interview dates and times with busy library staff and co-ordinating field visits to coincide with the steering group meetings in each authority. The transcription of interviews is very labour intensive and given the short timescale available for phase one, the project budget included funding for a research assistant to assist with the transcription and analysis of the data sets. A suitable candidate with appropriate experience was appointed on a temporary contract through the Leeds Metropolitan University Job Shop.

\section{Outline of the evaluation}

The first phase of the evaluation involved an analysis of the NYR activities in the two case study authorities of Calderdale and North Lincolnshire. Powell (2006), in providing an overview of evaluation research says that it should enhance knowledge and decision making and lead to practical applications. One way of exploring the challenging question of how libraries contribute to the cohesion and development of their communities is to use the concept of social capital.

Measuring impact evaluation is more difficult than collating statistics. This raises questions of how do you know you are making a difference and how can it be proved that a difference is being made. Markless and Streatfield $(2006,81)$ remind about the dangers of getting side tracked and looking at activities and processes when trying to evaluate impact, rather than concentrating on what difference you make. This NYR project has collected a range of qualitative evidence and quantitative data which can be interpreted to tell the story of the cultural provision in the case study authorities. The more refined the evidence collection, the clearer the picture is gained of the impact of the library service.

If we consider that evidence is information or data gathered to help address research objectives, how much evidence should you gather? According to Markless and Streatfield the pragmatic answer to this is 'as little as you need to make good decisions'. (2006,90) How much evidence you gather (or need) also depends on why you are collecting it, and in this NYR evaluation the researchers were gathering material as required and specified by the client in the project brief.

\section{The theoretical framework for the NYR evaluation project}

Three levels of analysis were used to evaluate the NYR impact issues in the case study authorities. The MLA Generic Social Outcome framework (GSOs) and the National Indicators (NI) from The New Performance Framework for Local Authorities \& Local Authority Partnerships (Department for Communities \& Local Government, 2007) were specified in the project brief. A third level, issues raised by the respondents, was added by the research team to enrich the analysis of the qualitative data.

\subsection{The Generic Social Outcomes framework}

A requirement of the research brief was to use the Generic Social Outcomes (GSOs) The GSOs have been developed by the MLA to help museums, libraries and archives to deliver against key agendas and maximise their contribution to communities. The framework is build around three key strands - 'Stronger and safer communities', 'Health and well-being' and 'Strengthening public life', each 
described by several second level themes. It is a means by which museums, libraries and archives can evidence their contribution to outcomes (Burns Owens Partnership, n.d.; MLA 2008). The GSOs are seen as an important tool because of the increased emphasis on outcomes as well as outputs. Linley and Herman (2008), in a report for MLA Yorkshire, argue that the GSO framework is useful for advocacy with potential partners and for funding applications.

\subsection{National Indicators}

The national indicator set has been developed as part of the Comprehensive Spending Review 2007 so that it reflects the Government's national priorities. The national indicator set 'will be the only measures on which central government will performance manage outcomes delivered by local government delivered alone or in partnerships'. (DCLG 2007,4)

\subsection{Individual issues of importance to the respondents}

The voice of the practitioner was considered an important aspect of the qualitative research in this evaluation project. Issues raised by respondents during interview were coded to enable the capture of data about individual concerns, interests and experiences.

\section{Methodology - an overview of the data collection strategies}

This was primarily a qualitative study involving the gathering, analysis, interpretation and presentation of narrative information. A variety of research methods were used to gather the data. Qualitative data was gathered via interviews and group discussions, which when analysed gave rise to quantitative data. Qualitative and quantitative data was also gathered from the case study authorities using desk research. In order to gain depth and rigour of analysis both the method and the process of analysis were triangulated. Bryman (2008) defines triangulation as the use of more than one method or source of data in the study of social phenomena so that findings may be crosschecked. This was undertaken through combinations and comparisons of multiple data sources, data collection and analysis procedures. In the context of this evaluation the researchers gained different perspectives on outcomes by gathering the views of staff, partners and users, as well as evidence from other sources using desk research. It was considered important to gather evidence from different groups of people, not just library staff. In this way evidence is more robust and therefore more credible if reinforced by other perspectives. Data was collected through focus group interviews with NYR steering group partners, focus group written responses to key questions, individual interviews and by using a variety of documentation and publicity materials from each authority. In this way rich data from the varied sources was gathered to generate different perspectives and to gain both a holistic picture of the development of the NYR initiatives across both case study local authorities.

\subsection{Interviewing}

Using interviews as a research strategy provides for powerful data collection because they use one-to-one interaction between researchers and interviewees 
(Teddlie and Tashakkori, 2009, 229). In-depth, face-to-face semi-structured interviews were conducted with key senior library staff in the two case study authorities. It was decided that semi structured interviews would be the most appropriate method to gather data in support of the research questions (Denscombe, 2003). Each local authority 'setting' was visited to undertake a range of data collection. There is much to be said about respondents being interviewed in their own environments; it is more probable that this will result in rich data through being embedded within their work context and also where they may feel most confident. Interviewing is an essential tool of enquiry-based research enabling the social science researcher to enter into other peoples' perspective and so elicit both information and opinions. It is the most frequently used qualitative research method to determine people's experiences in context and the significance and connotation that these offer (Hollway \& Jefferson, 2000). The interviews were conducted as conversations between fellow professionals as these are effective in gaining deeper insights into the realities of particular situations and the values and views of those participating. This type of qualitative data gathering provides deep insights and rich, detailed responses where there is an emphasis on the interviewee's point of view. An interview schedule was devised covering key questions about the target beneficiaries and partnership and cross departmental working (see appendix 1). The interview schedule was also designed to enable comparability of interviewing style as two researchers were carrying out the fieldwork. This allowed room for the evaluation team to pursue topics of particular interest or concern to the interviewee. The interviews were digitally recorded with the permission of the interviewees; this facilitated transcription of the data.

\subsection{Focus Group Interviews with NYR Steering Group members}

Members of the NYR Steering Groups in Calderdale and North Lincolnshire were invited to take part in a group discussion. The focus group methodology has been used for many years in market research and is now being used extensively in social research. There is an emphasis in the questioning on a particular fairly tightly defined topic and the emphasis is on interaction within the group and the joint construction of meaning. This is an effective and efficient way of gaining qualitative data through engaging a small number of people in an informal group discussion (Bloor, 2000, Bryman, 2008, Flick, 2002, Smith 2003). The group discussions focussed on a number of key questions designed to encourage discussion about partnership working and NYR legacy issues. The representatives of the partner organisations were invited to record their personal views and opinions on the NYR activities. Data gathered during the group interview discussions were digitally recorded for transcription, analysis and coding, as were written responses to key questions generated during the session by group members working in pairs. The participants raised issues, discussed their experiences and their own practice and activities in relation to the NYR campaign. As noted by Bryman (2008:490) the group interaction was seen as an important component of the discussion. 


\subsection{Documentary Evidence}

A range of supporting material in printed, digital and visual format was provided by the case study authorities and is it important to note that this material was readily available and not created specifically for the purposes of the evaluation research. The documentary evidence included reports, publicity leaflets and brochures, advertisements, photographs and website links. Quantitative data was provided on the increases in library membership and the number of people, families and children attending NYR events. The latter was supported by evaluation feedback from those who participated in local events.

\section{Reliability and validity of the evidence gathered}

In any research project it is important to provide a clear statement of methodological stance with a justification of the choice of the research methods to be employed (BERA, 2003, Denscombe, 2003, Robson, 2002). Qualitative research can be problematic in terms of reliability. Different observers may have different interpretations, data extracts may be brief and interpretations of interview transcripts may be undermined if everything is not recorded. Silverman $(2000,10)$ warns that there may be problems of 'anecdotalism' - how sound are the explanations if the researcher includes only 'a few telling examples' of some apparent phenomenon? It is incumbent on researchers to document procedures to ensure the methods used are reliable, that categories are used consistently and that the conclusions are valid. Researchers need to take care with data management and coding; protocols and instruments require construct validity in order to measure what the researchers intends them to measure. Both respondent validation and involving 'informed others' in the coding and analysis is important so that there is continual objective scrutiny to ensure the analysis is as reliable as possible. As stated earlier, triangulation involves using different approaches to eliciting responses so that it is examined from different perspectives to corroborate the analysis of recurring issues, patterns and themes. Multi-methods of gathering data provide different kinds of data on the same topic, allowing the researcher to see from different perspectives and to enhance reliability.

\subsection{Respondent validation}

The individual and group interviews were digitally recorded and then transcribed. The respondents were encouraged to participate actively in the research process and at each stage were asked to validate, respond and evaluate the research. The Data Protection Act confers the right for any person to have access to any personal data stored in relation to them (BERA, 2004:5, Bryman, 2008:119). It is good practice to provide respondents with a full transcription of their interview with a request for comments regarding accurate representation and establish reliability. In this way validity is checked with the practitioners concerned to ensure that the research team achieve accurate representation (Woods, 1999; Flick, 2002). 


\section{Analysing the data - the value of computer-assisted qualitative data analysis software (CAQDAS)}

Qualitative data elicited through interview transcripts is notoriously difficult to manage and needs to be well organised and structured to allow for coding and theory building. Good researchers come to know their raw data thoroughly as this facilitates the analysis, develops the emerging theory and aims to avoid any preconceptions (Campbell et al., 2004). Analysing data involves segmenting text and isolating items into categories to look for patterns. These may be particular factors repeated, explicit connections between different issues or consistent perspectives representing a view of a subject (Drever, 1995).

In recent years, one of the most notable developments in qualitative data research has been the development of computer software that can assist in the analysis of the data. Computer-assisted qualitative data analysis software, abbreviated as CAQDAS, handles many of the clerical tasks associated with coding and retrieving data. In this research project the MAXQDA software was used to support the systematic evaluation and interpretation of the data and made the coding and retrieval process more efficient. Coding is one of the key phases in the process of qualitative data analysis and MAXQDA facilitated the categorisation of each of the transcripts in as consistent a way as possible. The advantage of CAQDAS is that it can be effective in handling large volumes of coded data, enabling the researcher to track; retrieve; map; chart and redefine it quickly and accurately (Silverman, 2000). CAQDAS also enables the researchers to sift backwards and forwards through the data, adding new codes as well as removing those that do not gain enough evidence in the data (Siraj-Blatchford et al., 2002, Bryman, 2008)). It is the researcher who must determine the main areas for the analysis of the research and interpret the data - not the software package (SirajBlatchford et al., 2002).

MAXQDA proved to be a very effective tool that enabled the NYR data to be readily accessible and so continually interrogated. The process was extremely valuable in enabling a depth of analysis and interpretation, in developing consistent coding schemes and providing both qualitative and quantitative evidence. The quantitative evidence arises through the frequencies that a code is allocated to the dialogue of the respondents and indicated the strength of their issues, interests and concerns. The qualitative evidence derives from the richness of the individual narratives, group discussions and written responses. To ensure reliability the three members of the research team verified the interpretation and analysis of the way the codes were assigned to the data. The quantification and analysis of the codings within each individual interview and across all the interviews enabled the identification of what was noteworthy for the respondents.

The MAXQDA CAQDAS package enabled the researchers to code and validate the data as required by MLA (Yorkshire) clients by using the Generic Social Outcomes framework and the Public Service Agreements (PSA) National Outcome and Indicator Set. A third level of coding was developed to identify issues raised by the interviewees. In this way the data analysis was triangulated in order to gain deeper levels of meaning through these three dimensions. This first phase of the research project has already generated a substantial data set and the 
use of MAXQDA software will facilitate phase two of the NYR evaluation scheduled to be undertaken between September and December 2009. The software stores the data and the coding structures and will facilitate a comparison of the data gained through the longitudinal study; this evidence can be used as comparative data set for the second phase.

\section{Initial findings from phase one of the evaluation study}

The brief and specification for the evaluation project required the evaluation to investigate the impact of the NYR in two sample local authorities in relation to target beneficiaries and partnership and cross departmental working. This paper does not identify specific locations for activities but endeavours to present generic findings and the analysis has been effected across all data sets. The sections below discuss the initial findings from the three levels of analysis.

\subsection{Initial Findings from the Generic Social Outcomes framework}

The phase one evaluation has found considerable evidence of NYR related activities in supporting the three primary social outcomes 'Stronger and Safer Communities', 'Health and Well-Being' and 'Strengthening Public Life'.

\subsubsection{GSO Stronger and Safer Communities}

In examining the project objectives of 'Target beneficiaries' and 'Partnership and cross departmental working' there is evidence to indicate the second level of social outcome themes. There is very strong evidence for 'improving group and inter-group dialogue and understanding', this came from all layers of analysis and from all participating groups. The coding and analysis demonstrated that this was the strongest outcome overall from the NYR activities. 'Supporting cultural diversity and identity' was also identified as being a strong theme throughout the data collection. A range of different groups were identified as key target groups and there was varied cultural diversity within the target groups in both case study authorities.

The Manga event brought all sorts of people in to the library who have never been before. I want to go one step further and consult those people about using our service.

'Encouraging familial ties and relationships' also merited attention as there was interest in supporting family groups. Some projects focussed on activities aimed at hard to reach groups, some added value to original users while others were new ideas inspired by the opportunities of the NYR partnerships.

We are doing a lot of great stuff, including breakthrough initiatives for some groups e.g. making materials for homeless people. We have never done that before.

We are now thinking about legacy. We don't just want to run events and then stop it at the end of NYR. We are also thinking about community engagement so I want to use some of the people we have made contact with to improve our community engagement in future. 


\subsubsection{GSO Strengthening Public Life}

A very strong second tier theme was improving services:

We have various targets and agendas that drive us. The leading agenda is the Equalities Impact Assessment, which in library terms means identifying new communities and providing a service for them. The NYR has pushed towards a service located outside the library. Were it not for the NYR we would have contented ourselves with providing stock within the library and the outreach might not have happened. The actuality is that the NYR gave us the steering group that provided us with the contacts that we needed to do that.

There was also evidence that partnership projects were being used to reach target beneficiaries:

It has been through the partnerships we have been working with - housing benefits, sheltered housing, and the hospital library - we find it hard to reach those target groups. Those kinds of people don't tend to come into libraries. We need to make contact with the people who work with them on a regular basis.

Other second tier themes that generated an evidence base were 'Safe, inclusive and trusted public spaces' and 'Building the capacity of community and voluntary groups'.

We are taking out of this year a commitment to changing the pattern of city and local libraries, where most things happen. We will hopefully soon have two more places and hopefully we will have more. In terms of redevelopment, a place becomes a hub if it becomes a place where the community gets used to expecting exciting and valuable reading events, workshops, festivals on a regular basis. I hope that will emerge from the NYR.

We suddenly got access to everyone else's knowledge and could piggy back on other people's events. The NYR was a way of reaching other staff. People don't always respond to emails - meeting people makes such a difference.

\subsubsection{GSO Health and Well-Being}

Within this GSO the strongest second tier theme was 'Helping children and young people to enjoy life and make a positive contribution'. 'Encouraging healthy life styles and contributing to mental and physical-well being' also merited attention. Some of the projects the case study teams have started will last beyond the year of NYR and they hope they will become embedded and so continue to run and not be dependent on individuals

We are reaching the homeless, new immigrants, people with mental health problems - the potential is much more than we are doing. I hope that we will maintain the commitment to be creative.

We have staged a Third poetry competition aimed at adult learners across the region. There were lots of entries. People who had never been in a library read out poems in front of a whole audience. 


\subsection{Initial Findings from National Indicators}

From the evidence gathered, the coding using the National Indicators (NI) mirrored the findings of the GSOs. The analysis using the NI demonstrated that these two case study local authorities have the needs of their target groups at the heart of their work. There was considerable evidence of how they were working to build stronger communities. The coding analysis using the PSA National Indicators demonstrated that the evidence gathered from the case study authorities held 'Stronger communities' to be their most important issue. Obviously the 'Use of public libraries (N 9) was very strong, but also 'Belonging to neighbourhood' and 'People from different backgrounds' were significant. The evidence shows that they had the needs of 'children and young people', 'adult health and wellbeing' and tackling exclusion and promoting equality inherent in what they do.

\subsection{Initial Findings from Interviewees' Issues}

The voice and experiences of the practitioner proved to be a really important level of analysis. Significant issues would be omitted if the views and concerns and issues of the individual were not taken into account. Across all the data sets there were noteworthy issues that are not addressed either the GSO or the NI. For any evaluation of library services to be effective it is important to elicit the voices of those engaged in the management and delivery of the services and the development of new initiatives. The voice of the practitioner needs to be heard and taken into account by those who are involved in policy making.

The interviewees felt extremely strongly that partnerships were a key aspect of the NYR activities. The steering groups in both case study local authorities had worked successfully in different ways. These were a very positive outcome in the two locations, driven by highly motivated practitioners who were using the NYR as a focal point for drawing together their work, showcasing new projects and refreshing ideas about existing provision. The NYR proved to be an opportunity for stimulation and was effective in further developing existing and new partnerships. The interviewees reflected positively upon the challenges offered by the NYR. These included initial problems about NYR promotion and publicity and the difficulties of getting the year underway with minimal time to plan and implement. Concerns were raised about the lack of clarity about what the NYR would actually entail, particularly as no additional funding was available. There were issues about personnel and staffing where service provision was already under some considerable pressure.

Legacy was a noteworthy issue raised by the interviewees. There was a feeling that the enthusiasm generated by the NYR focus should be fostered and sustained. There is a real willingness to continue to develop and some early evidence on opportunities for partnership work to be embedded in the planning and delivery of local authority agendas. This will be interesting to review at the next phase of the evaluation as there is a very strong desire to move beyond the need for dependency on personal contacts and ad hoc arrangements into more sustainable partnerships.

Mirroring the GSO and NI findings, the diversity of the target groups was evidenced. The interviewees spoke about provision that targeted adults, young 
people and children; diverse ethnic communities; migrant workers; specific workforce groups; hard to reach groups such as the homeless and those with mental health needs. The case study data showcases a wide range of activities and events offered under the banner head of the NYR campaign.

\section{Results \& Implications of the phase one data collection}

The analysis of data from the first phase has suggested 6 key themes:

- Improving services and sharpening the focus of what is on offer.

- Working in partnership and strengthening partnerships

- Dealing with challenges

- The importance of activities and events

- Stronger communities - with a particular emphasis on improving group and inter-group dialogue and understanding and supporting cultural diversity and identity

\section{- Legacy of the NYR}

These key issues will help to frame the evidence base for phase two of the evaluation project. Evaluation research should enhance knowledge and decision making and lead to practical applications. The MLA project brief proposes that the same methodology should be used to revisit the same authorities to measure the distance travelled on the areas of investigation from phase one. The researcher team will repeat the process in September - December 2009 using the same theoretical framework. It is anticipated that this will allow sufficient time for a number of the partnership initiatives to have matured and will be leading up to repeat opportunities for some events.

\section{Conclusion}

These are the issues that have been flagged up following phase one; the phase two study will enable a deeper analysis. In this way, longitudinal study would illuminate social change and improve the understanding of causal influences over time. The first phase of the NYR evaluation has developed a framework for analysing future data and provides a means of tracking progress. The evaluation research will provide material that local library authorities can use for advocacy with a range of audiences including local and central government. The interim report prepared for MLA Yorkshire responds to the challenging question of how libraries can contribute to the cohesion and development of their communities and how the concept of social capital might be used. Stronger and safer communities and the improvement of group and inter group dialogue and understanding proved to be some of the most significant issues resulting from this phase one evaluation. The NYR has certainly had an impact on the visibility of reading in communities and the analysis of the evidence gives an indication of the enthusiasm and professionalism involved in delivering the campaign. The feeling of achievement and accomplishment might be best summed up in the very positive comment 'Why can't every year be a National Year of Reading?' 


\section{References}

BERA (British Educational Research Association) (2004) Revised ethical guidelines for educational research. Notts: BERA. URL:

http://www.bera.ac.uk/files/2008/09/ethica1.pdf [accessed 07.09.09].

Bloor, M., Frankland, J., Thomas, M. and Robson, K. (2000) Focus groups in social research. London: Sage

Burns Owens Partnership (n.d.) MLA: Social outcomes for museums, libraries and archives. Prototype social outcomes framework. URL:

http://www.malmo.se/download/18.3964bd3611d8d4a5d1c800027714/gso_frame work_12198.pdf [accessed 12.09.09]

Bryman, A. (2008) Social research methods. $3^{\text {rd }}$ Ed. Oxford: Oxford University Press.

Campbell, A., McNamara, O. and Gilroy, P. (2004) Practitioner research and professional development in education. London: Paul Chapman Publishing.

Cohen, L., Manion, L. and Morrison, K (2003). Research methods in education. $5^{\text {th }}$ Ed. London: Routledge Falmer.

DCLG Department for Communities and Local Government (2007) The new

Performance Framework for Local Authorities and Local Authority Partnerships:

Single Set of National Indicators. London: Department for Communities and Local Authorities.

Denscombe, M. (2003) The good research guide for small scale research projects. $2^{\text {nd }}$ Ed. Milton Keynes: Open University Press

Drever, E. (1995) Using semi-structured interviews in small scale research.

Scottish Council for Research in Education.

Flick, U. (2002) An introduction to qualitative research. London: Sage.

Hollway, W. and Jefferson, T. (2000) Doing qualitative research differently. London: Sage.

Linley, R. and Herman, C. (2008) Yorkshire GSO Pilot Programme. Report for MLA Yorkshire.

Markless, S. and Streatfield, D. (2006) Evaluating the impact of your library. London: Facet Publishing.

MLA (2008) Inspiring learning: Generic Social Outcomes. URL:

http://www.inspiringlearningforall.gov.uk/toolstemplates/genericsocial/ [accessed 12.09.09].

Powell, R.R. (2006) Evaluation research: An overview. Library Trends, 55(1), 102-120.

Robson, C. (2002) Real world research: a resource for social scientists and practitioner-researchers. $2^{\text {nd }}$ Ed. Oxford: Blackwell

Silverman, D. (2000) Doing qualitative research. London: Sage. 
Siraj-Blatchford, I., Sylva, K., Muttock, S., Gilden, R. and Bell, D. (2002) Researching effective pedagogy in the early years. London: Institute of Education.

Smith, J. (2003) Qualitative psychology: a practical guide to research methods. London: Sage.

Teddlie, C. and Tashakkori, A. (2009) Foundations of mixed methods research: Integrating quantitative and qualitative approaches in the social and behavioural sciences. London: Sage

Woods, P. (1999) Successful writing for qualitative researchers. London:

Routledge.

\section{Acknowledgments}

Thanks are due to the funders MLA Yorkshire, Renaissance Yorkshire and Arts Council England, Yorkshire. The researchers also thank the senior staff at Calderdale and North Lincolnshire Libraries who were interviewed, and to the members of the NYR Steering Groups in those authorities for their participation in the focus group discussions. 


\section{Appendix 1}

\section{National Year of Reading evaluation project \\ Interview Schedule for library staff in the Calderdale and North Lincolnshire case study authorities}

\section{Section 1: Target beneficiaries}

Please can you tell me about what are you doing to promote the NYR in [your authority] with the target groups.

What opportunities has the NYR offered for developing new projects and initiatives?

In what way has the NYR changed the way you are supporting the target groups.

What do you think are the likely legacy benefits for the NYR in your authority?

\section{Section 2: Partnership and cross departmental working}

How are partnerships with other organisations being used to promote the NYR in [your authority]?

What NYR partnerships activities do you feel are working well in [your authority]?

What are the challenges for your staff in working in NYR partnership activities?

How has the NYR effected what you are doing in your everyday work? 